\title{
Inadequate Use of Prenatal Services Among Brazilian Women:The Role of Maternal Characteristics
}

CONTEXT: To improve the uptake of prenatal care, it is important to know how the use of prenatal care varies by ma-
ternal attitudes and social and demographic factors.

METHODS: Information about social and demographic variables, prenatal care, parity, pregnancy planning, abortion attempts, satisfaction with pregnancy and satisfaction with the relationship with the child's father was collected from 611 postpartum women in Porto Alegre in southern Brazil. Multinomial logistic regression was used to evaluate associations between these variables and whether the women's use of prenatal care was adequate, partially inadequate or inadequate.

RESULTS: About 40\% of women had inadequate or partially inadequate prenatal care. After adjustment for other covariates, including satisfaction with the pregnancy, women having an unplanned pregnancy were significantly more likely to have had inadequate care than women who had planned their pregnancy (odds ratio, 2.0). Not living with the child's father (2.8) and dissatisfaction with pregnancy (2.1) were also associated with inadequate use of prenatal care. Women having their second or higher order birth were significantly more likely to report inadequate use of prenatal care than women having their first birth (3.9-9.0). Household income was inversely associated with inadequate use of care.

CONCLUSIONS: The study suggests that maternal attitudes may be important for adequate prenatal care. Interventions should be created to encourage women with negative maternal attitudes to use prenatal care and to ensure that they have access to the care they need.

International Perspectives on Sexual and Reproductive Health, 2009, 35(1):15-20

Prenatal care is a strong predictor of positive pregnancy outcomes, ${ }^{1}$ and has a substantial impact on maternal and child mortality. ${ }^{2-5}$ Initiation of prenatal care during the first trimester of pregnancy allows for timely diagnosis and treatment of numerous health problems. These health benefits are enhanced among socially disadvantaged, highrisk populations that usually experience difficulty in obtaining adequate prenatal care. ${ }^{6}$

Difficulty in obtaining prenatal care among nonwhite women in the United States is associated with late initiation of prenatal care and fewer consultations. ${ }^{7}$ Similar issues regarding unequal access and quality of prenatal care have been investigated in Brazil. ${ }^{8}$ Social and demographic factors appear to be important for prenatal care. Women with no prenatal care or inadequate prenatal care are usually younger and unmarried, have lower education and have had more births. ${ }^{9-13}$ However, there is some inconsistency in the literature; in some studies, use of prenatal care was not associated with marital status or parity. ${ }^{14}$

Although some studies have explored the role of maternal characteristics, few studies have investigated maternal attitudes toward pregnancy, such as whether the pregnancy was unintentional, whether the woman had attempted an abortion and how satisfied the woman was during and after pregnancy. ${ }^{6,11,15}$ Our study provides a unique opportunity to examine these features in a popu- lation representative of low-income users of public hospitals in southern Brazil.

Maternal attitudes toward pregnancy may be as important as structural barriers in the determination of late initiation of prenatal care. ${ }^{16}$ The objective of this study was to assess the role that maternal characteristics, including both attitudes related to pregnancy and those related to social and demographic factors, play in the inadequate use of prenatal services.

\section{METHODS}

Data

Women who gave birth at one of three major public maternity hospitals in Porto Alegre, southern Brazil, were recruited for study participation between May and December of 2002. Of the 611 women who agreed to participate (there were no refusals), all had complete data on prenatal care and are included in the analyses. These women were controls in a larger incident case-control study for investigating the association between maternal periodontitis and perinatal outcomes; a detailed explanation of the case-control study may be found elsewhere. ${ }^{17}$ The next two births following a case in the same hospital were eligible to be controls. Exclusion criteria were multiple gestations, maternal diabetes, having delivered a stillbirth at less than 28 weeks' gestation and having delivered an in
By Diego G. Bassani, Pamela J.Surkan and Maria Teresa A. Olinto

Diego G. Bassani is epidemiologist, Centre for Global Health Research, Li Ka Shing Knowledge Institute, St. Michael's Hospital,

Toronto, Ontario,

Canada. Pamela J.

Surkan is assistant professor, Department of International Health, Johns Hopkins Bloomberg School of Public Health, Baltimore, MD, USA. Maria Teresa A. Olinto is director, Programa de Pós-graduação em Saúde Coletiva, Universidade do Vale do Rio dos Sinos, São Leopoldo, Brazil. 
TABLE 1. Selected characteristics of a sample of women who gave birth in Porto Alegre, Brazil, May-December 2002

\begin{tabular}{|c|c|}
\hline Characteristic & $\%$ \\
\hline Age & $(\mathrm{N}=608)$ \\
\hline $10-19$ & 22.1 \\
\hline $20-24$ & 26.3 \\
\hline $25-29$ & 23.7 \\
\hline $30-34$ & 16.1 \\
\hline $35-46$ & 11.8 \\
\hline Income (in US\$) & $(\mathrm{N}=611)$ \\
\hline 1 st tertile $(<\$ 38.20)$ & 34.4 \\
\hline 2nd tertile $(\$ 38.20-\$ 74.30)$ & 32.1 \\
\hline 3rd tertile $(>\$ 74.30)$ & 33.5 \\
\hline Education (in yrs.) & $(\mathrm{N}=611)$ \\
\hline$<5$ & 13.8 \\
\hline $5-7$ & 32.0 \\
\hline$\geq 8$ & 54.2 \\
\hline Skin color & $(\mathrm{N}=611)$ \\
\hline White & 75.5 \\
\hline Nonwhite & 24.5 \\
\hline Parity & $(\mathrm{N}=608)$ \\
\hline 1 & 39.5 \\
\hline $2-3$ & 41.1 \\
\hline$\geq 4$ & 19.4 \\
\hline Living with child's father & $(\mathrm{N}=609)$ \\
\hline Yes & 84.6 \\
\hline No & 15.4 \\
\hline Satisfaction with relationship with child's fathert & $(\mathrm{N}=455)$ \\
\hline Mean & $8.8[1.5]$ \\
\hline Planned pregnancy & $(\mathrm{N}=609)$ \\
\hline Yes & 36.1 \\
\hline No & 63.9 \\
\hline Satisfied with pregnancy (prenatal) & $(\mathrm{N}=609)$ \\
\hline Yes & 73.4 \\
\hline No & 26.6 \\
\hline Satisfied with pregnancy/child (postnatal) & $(\mathrm{N}=608)$ \\
\hline Yes & 97.5 \\
\hline No & 2.5 \\
\hline Attempted abortion & $(\mathrm{N}=607)$ \\
\hline Yes & 4.1 \\
\hline No & 95.9 \\
\hline Any prenatal care & $(\mathrm{N}=611)$ \\
\hline Yes & 95.7 \\
\hline No & 4.3 \\
\hline Initiation of prenatal care (trimester) & $(\mathrm{N}=579)$ \\
\hline 1st & 71.9 \\
\hline 2nd & 24.8 \\
\hline $3 r d$ & 3.3 \\
\hline No. of prenatal care visits & $(\mathrm{N}=586)$ \\
\hline$<6$ & 23.7 \\
\hline$\geq 6$ & 76.3 \\
\hline Prenatal care & $(\mathrm{N}=600)$ \\
\hline Adequate & 60.8 \\
\hline Partially inadequate & 21.2 \\
\hline Inadequate & 18.0 \\
\hline
\end{tabular}

tRange, $0-10$; higher scores indicate greater satisfaction with relationship. Notes: Data are percentages unless otherwise noted. Ns vary because of missing responses, because responses were limited to only those reporting any prenatal care, or both. Figure in brackets is standard deviation. fant with severe physical defects that could compromise the chances of survival. The newborn's birth weight was not a criterion for the mother's participation. All women signed an informed consent form before enrollment. The study was approved by the review boards at the three hospitals and at the Federal University of Pelotas.

All women were interviewed at the hospital within 24 hours of delivery. Interviewers were medical students trained to gather information through a structured questionnaire. The following information was collected: socioeconomic and demographic variables (income; completed years of education; age; race, dichotomized as white or nonwhite); number of births; and family support (whether respondent was living with child's father). Mothers provided information about the income of all members of the household; this was used to calculate each household's monthly per capita income.

The variables relating to maternal attitudes toward the current pregnancy were whether the pregnancy had been planned, whether the woman had attempted to abort the pregnancy, whether the respondent had been satisfied with the pregnancy during the prenatal period, whether the respondent was satisfied with the pregnancy during the postnatal period and how satisfied she was with her relationship with the child's father (from $0=$ "completely dissatisfied" to 10="completely satisfied").

The prenatal care outcome was categorized as adequate, partially inadequate and inadequate. Adequacy of prenatal care was based on the Kessner index, ${ }^{18}$ which is in line with norms specified by the Brazilian Ministry of Health. ${ }^{10}$ For term births (37 weeks' gestation or more), adequate prenatal care was defined as at least six visits before completion of the pregnancy, initiated during the first trimester. Partially inadequate prenatal care was defined as either late initiation of care (during the second or third trimester) or fewer than six consultations, and inadequate prenatal care was defined as both late initiation and fewer than six consultations.

For women who had had preterm births, the number of follow-up visits was adjusted for pregnancy duration. Therefore, the adequate number of visits was five visits for pregnancies lasting between 33 and 36 weeks, four visits for those between 29 and 32 weeks, three visits for those between 24 and 28 weeks and two visits for pregnancies lasting less than 24 weeks.

\section{Analysis}

Statistical analyses were performed using Stata 8.0. The accuracy of data entry was ensured by duplicate entry and cross-checks against the databases. Because the dependent variable had three categories (adequate, partially inadequate and inadequate prenatal care), we used multinomial logistic regression to estimate odds ratios and 95\% confidence intervals. This approach avoids the information loss that can occur in logistic regression when responses are collapsed into two categories.

We used a multivariable conceptual framework for variable selection and modeling. ${ }^{19}$ Our model included so- 
cioeconomic and demographic variables (Level I), followed by reproductive history and family support (Level II). Variables at Level III included measures related to maternal attitudes: having planned the pregnancy, having attempted an abortion, having felt satisfied during pregnancy and having felt satisfied within the first 24 hours after delivery.

Measures were included in the multivariable models only when a probability of association greater than $80 \%$ was observed in the bivariate analysis $(\mathrm{p}<.20)$. For the multinomial logistic model, variables from Level I were entered using backwards elimination. Those with a $\mathrm{p}$ value below 10 were retained as covariates in subsequent models. Next, variables from Level II were added and were adjusted for the variables remaining from Level I. This procedure was repeated for Level III.

\section{RESULTS}

Of the 611 women who took part in the study, the mean age was 25.5 years (standard deviation, 6.8; not shown) and the mean monthly per capita income was US\$63.30 (standard deviation, \$27.50). The mean number of years of education was 8.2 (standard deviation, 7.9).

Twenty-two percent of the women were adolescents, and approximately $40 \%$ had given birth for the first time (Table 1). More than 15\% of respondents did not live with their child's father. A high percentage of pregnancies were not planned (64\%) and 27\% reported that they had been dissatisfied with their pregnancy during the prenatal period. After delivery, only 3\% of mothers were dissatisfied with the pregnancy or their child.

Attempted abortions were reported by $4 \%$ of the women. Further analyses revealed that the $12 \%$ of women who reported being dissatisfied both during pregnancy and after delivery were significantly more likely to have attempted an abortion than those who reported being satisfied either during their pregnancy or after delivery (not shown).

Overall, $61 \%$ of the women fulfilled the criteria of having received adequate prenatal care, while $4 \%$ had had no prenatal care. Partially inadequate prenatal care was reported by $21 \%$ of women. Late initiation, more than frequency of visits, contributed to lower levels of prenatal care-about $69 \%$ of the 235 women who received inadequate or partially inadequate care had their first visit in the second or third trimester (not shown).

\section{Multivariate Analysis}

Higher income was strongly associated with decreased odds of inadequate and partially inadequate prenatal care and higher education was associated with decreased odds of partially inadequate prenatal care (Table 2). In addition, being nonwhite was associated increased odds of inadequate prenatal care (odds ratio, 1.7). Women who had had four or more births were significantly more likely than women with only one child to report partially inadequate prenatal care and to report inadequate prenatal care (2.5 and 5.2, respectively); women with two or three children were also more likely than women with one child to have

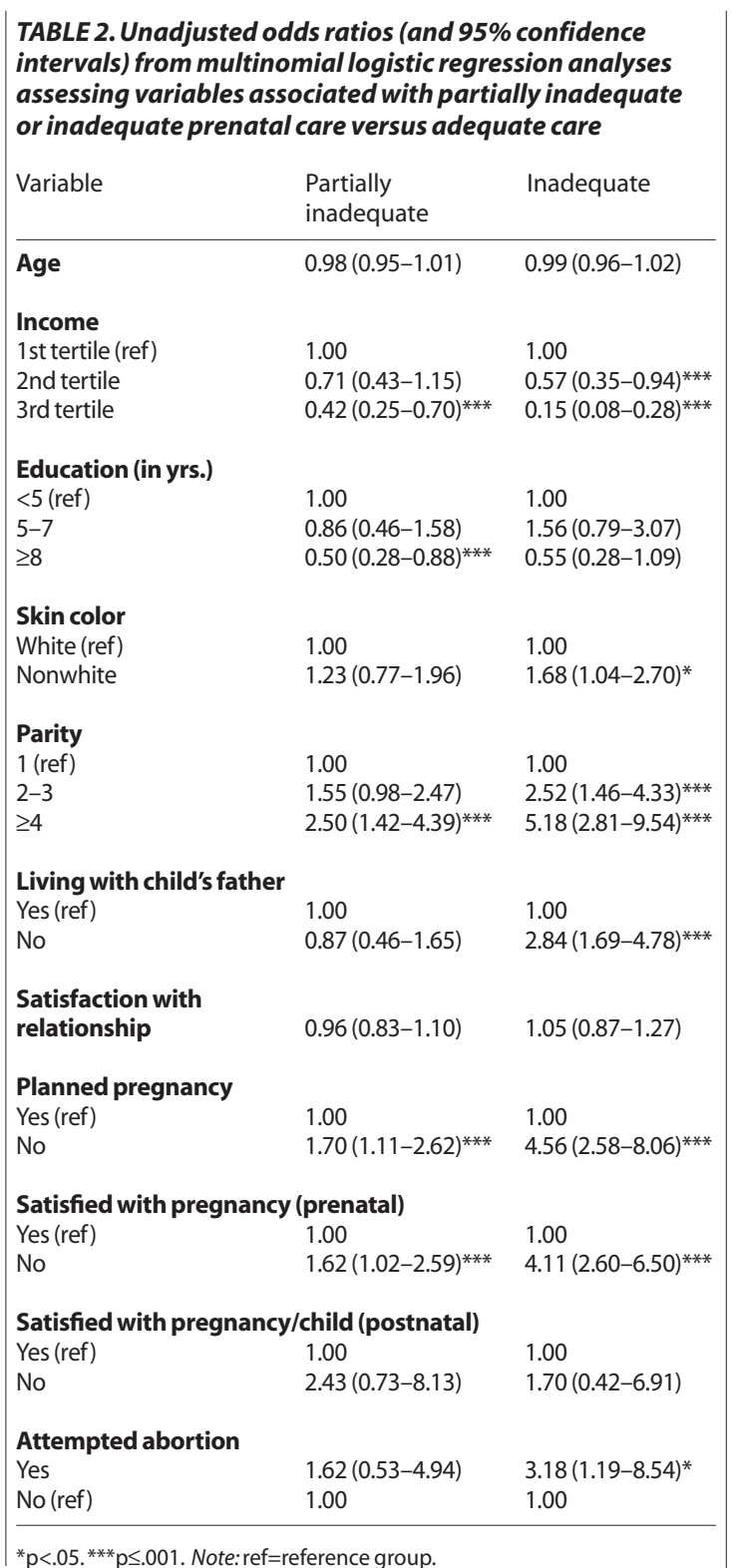

received inadequate care (2.5). Women who were not living with their child's father were significantly more likely than those who were to report inadequate prenatal care (2.8). We observed an association between unplanned pregnancy and dissatisfaction during pregnancy with partially inadequate prenatal care (1.7 and 1.6, respectively) and with inadequate prenatal care ( 4.6 and 4.1 , respectively). Finally, having attempted abortion was associated with increased odds of inadequate prenatal care (3.2).

After simultaneous adjustment for Level I variables, race and education were not associated with adequacy of prenatal care (Table 3, page 18). Furthermore, the magnitude of their effects was attenuated after income was controlled for. Higher income, on the other hand, was strongly inversely associated with inadequate prenatal care in models adjusted for race and education. Respondents in the highest income tertile were less likely than poorer women to have received either partially inadequate (odds ratio, 
TABLE 3. Adjusted odds ratios (and 95\% confidence intervals) from multinomial logistic regression analyses assessing variables associated with partially inadequate or inadequate prenatal care versus adequate care

\begin{tabular}{l} 
Variable \\
\hline LEVEL 1 \\
Age \\
Income \\
1st tertile (re $)$ \\
2nd tertile \\
3rd tertile \\
Education \\
Skin color \\
White (ref) \\
Nonwhite \\
LEVEL II \\
Parity \\
1 (ref) \\
2-3 \\
$\geq 4$
\end{tabular}

Partially Inadequate

$0.99(0.96-1.02)$

$0.99(0.96-1.03)$

1.00

$0.69(0.43-1.13)$

$0.43(0.26-0.72)^{* * * *}$

$0.96(0.88-1.04)$

1.00

$1.06(0.66-1.72)$

$$
1.00
$$

$1.81(1.07-3.06)^{* * *}$

$3.30(1.58-6.91)^{* * *}$

Living with child's father

Yes (ref)

No

1.00

$0.76(0.38-1.50)$

LEVEL III

Planned pregnancy

Yes (ref)

No

1.00

$1.34(0.82-2.20)$

Satisfied with pregnancy (prenatal)

Yes (ref)

No

1.00

$1.19(0.69-2.04)$

Attempted abortion

Yes

No (ref)

$1.37(0.42-4.55)$

1.00
$1.26(0.77-2.07)$
1.00

1.00

$0.57(0.35-0.94)^{* * * *}$

$0.14(0.07-0.28)^{* * * *}$

$0.92(0.85-1.01)$

1.00

$3.93(2.05-7.53)^{* * *}$

$9.03(3.82-16.30)^{* * *}$

1.00

$2.74(1.53-4.92)^{* * *}$

1.00

$1.96(1.01-3.79)^{*}$

1.00

$2.12(1.22-3.67)^{* *}$

$1.55(0.51-4.68)$

1.00
${ }^{*} \mathrm{p}<.05 .{ }^{* *} \mathrm{p}<.01 .{ }^{* * *} \mathrm{p} \leq .001$. Notes: Estimates are adjusted for the hospital where delivery occurred and maternal age. Variables that were not significant at $p<.05$

for either outcome were not included in the final model. ref=reference group.

$0.4)$ or inadequate prenatal care (0.1).

After adjustment for income (the only variable retained from Level I), the association between parity and prenatal care was stronger. Women reporting four or more births were significantly more likely than women experiencing their first birth to report partially inadequate prenatal care (odds ratio, 3.3) or inadequate prenatal care (9.0). Women reporting two or three births were also more likely than those reporting one to have received partially inadequate (1.8) or inadequate prenatal care (3.9). Not living with the child's biological father was strongly related to inadequate prenatal care after adjustment for income and parity (2.7).

In models adjusted for income, parity and whether the woman was living with the child's father (Level I and II variables), unplanned pregnancy and dissatisfaction with the pregnancy remained associated with inadequate care (odds ratios, 2.0 and 2.1, respectively). There was no evidence that having attempted an abortion during pregnancy was associated with use of prenatal care. However, it should be noted that a very low proportion of women in our sample reported having attempted an abortion, and women who had been successful in inducing an abortion were not included in our study.

\section{DISCUSSION}

The present study investigated the role of maternal attitudes and social and demographic characteristics on adequate use of prenatal care in a sample of low-income women from southern Brazil. Unplanned pregnancy, dissatisfaction with the pregnancy, higher parity and not living with the child's father were strongly associated with inadequate prenatal care. There was a strong and significant income gradient associated with inadequate prenatal care: Within this fairly homogeneous low-income population, the odds of inadequate use of prenatal care rose sharply as income declined.

An increased risk of inadequate prenatal care was observed among women with unplanned pregnancies. Little is known about the role of unwanted or unplanned pregnancies as barriers to prenatal service use. An association between unplanned pregnancies and late initiation of care has been previously reported. ${ }^{9}$ However, other research has failed to find an association between unplanned pregnancy and adequate use of prenatal care. ${ }^{14}$ On the other hand, one study has linked unwanted pregnancy to a higher risk of neonatal death: Women with an unwanted pregnancy were significantly more likely than those who had planned their pregnancy to deliver a child who died within the first 28 days of life. ${ }^{20}$

In our study, a woman's satisfaction with her pregnancy plays an important role in her use of prenatal care. Our results provide evidence to complement descriptive, unadjusted results from a previous cross-sectional study from Rio de Janeiro. Among adolescents interviewed in the immediate postpartum period, those who reported satisfaction with their pregnancy were likely to have attended more prenatal appointments. ${ }^{11}$ Furthermore, our findings are congruent with those of Tough et al., who showed that low satisfaction predicts late initiation and low frequency of prenatal care. ${ }^{15}$ In the case of our study, because of the cross-sectional nature of the study design, we cannot rule out the possibility of reverse causality-that receiving adequate prenatal care may also positively influence satisfaction during pregnancy.

Although the relationship between having attempted an abortion and use of prenatal care did not reach statistical significance in our sample, further study in a larger sample is warranted.

We observed a dose-response association between parity and inadequate prenatal care. This association remained significant after adjustment for socioeconomic status. Other studies report similar findings, 9,10,21,22 suggesting that regardless of one's knowledge about service availability and previous use of prenatal care services, each additional birth considerably reduces the odds of appropriate use of prenatal care. ${ }^{23}$ However, previous results have not always been consistent, with some research showing parity to be unrelated to adequacy of prenatal care. ${ }^{14}$ One explanation for the relationship we found be- 
tween higher parity and reduced use of prenatal care could be that some women who have previously given birth consider themselves to have sufficient knowledge and experience with pregnancy to deal with it on their own.

Not living with the child's father during pregnancy was associated with significantly higher odds of inadequate use of prenatal care than living in a household in which the child's father was present (odds ratio, 2.7). The absence of the father is known to have adverse effects on children's health and development, ${ }^{24}$ and is believed to influence other maternal behaviors. In samples of U.S. women, poor health behaviors have been observed among single mothers. ${ }^{9,16}$ Other research on social support generally has reported an association between lack of a supportive person during pregnancy and late prenatal care. ${ }^{9}$

Several studies report an association between inadequate prenatal care and child mortality. ${ }^{25,26}$ Improvement in access to and in the quality of prenatal care (the timing of initiation, adherence to visit schedule, as well as the content of the care) is suggested as a route to reduce child mortality and adverse perinatal outcomes. ${ }^{27}$ Factors such as maternal satisfaction during pregnancy and family structure and support may be important when attempting to reduce preventable child mortality through better use of prenatal care. Future qualitative work may help identify factors that contribute to maternal satisfaction during pregnancy as well as those that act as barriers to prenatal care. Recent work has highlighted the importance of factors such as maternal depression in early child nutritional outcomes. ${ }^{28,29}$

Because our data are cross-sectional, we are not able to infer causation; therefore, further research is needed to establish the direction of these associations. Our sample was made up largely of low-income individuals using public medical facilities in Brazil, thus limiting generalizability to similar populations. Nonetheless, study of this subset of the population is particularly important, because such low-income groups have been most vulnerable to adverse maternal and child health events. One limitation of our analysis is that our variable indicating adequacy of prenatal care does not provide information about the content or quality of the prenatal care received. To overcome this problem, we attempted to use the Adequacy of Prenatal Care Utilization (APNCU) index. ${ }^{30}$ However, with the APNCU index, the prevalence of adequate prenatal care falls to $9 \%$, providing low statistical power. For this reason, and to be consistent with prior large studies in Brazil, ${ }^{4}$ we used the classification system of Kessner and colleagues. Since interviews were typically conducted in shared hospital rooms following the birth, it is possible that the lack of privacy may sometimes have led to misreporting. However, we believe that in most cases, socially desirable responses (such as underreporting of dissatisfaction with pregnancy or unintended pregnancy, or overreporting of the number of prenatal visits) would contribute to an artificial attenuation of the observed associations.

Our findings suggest that negative maternal attitudes, such as dissatisfaction with pregnancy, are associated with inadequate use of prenatal care. Our results further imply that economically disadvantaged, single women who have several children form a population at high risk for inadequate prenatal care. Future research is needed to establish the complex relationships between these variables. For instance, the absence of the father could be merely another component in the chain of events that evolve from an unintended or unwanted pregnancy. Now that important maternal attitudes and social and demographic factors have been identified, interventions should be created to encourage women with these characteristics to use prenatal care and to ensure that they have access to the care they need.

\section{REFERENCES}

1. Kogan MD et al., Trends in twin birth outcomes and prenatal care utilization in the United States, 1981-1997, Journal of the American Medical Association, 2000, 284(3):335-341.

2. Hueston WJ et al., Delayed prenatal care and the risk of low birth weight delivery, Journal of Community Health, 2003, 28(3):199-208.

3. Buck GM et al., Timing of prenatal care and risk of sudden infant death syndrome, International Journal of Epidemiology, 1990, 19(4): 991-996.

4. Laditka SB et al., Potentially avoidable maternity complications: an indicator of access to prenatal and primary care during pregnancy, Women \& Health, 2005, 41(3):1-26.

5. Menezes AMB et al., Infant mortality in Pelotas, Brazil: a comparison of risk factors in two birth cohorts, Revista Panamericana de Salud Pública, 2005, 18(6):439-446.

6. Paredes I et al., Factors associated with inadequate prenatal care in Ecuadorian women, International Journal of Gynaecology \& Obstetrics, 2005, 88(2):168-172.

7. Park JH, Vincent D and Hastings-Tolsma M, Disparity in prenatal care among women of colour in the USA, Midwifery, 2007, 23(1):2837.

8. Dias-da-Costa JS et al., Inequalities in clinical breast examination in São Leopoldo, Rio Grande do Sul, Brazil, Cadernos de Saúde Pública, 2007, 23(7):1603-1612 (in Portuguese).

9. Nothnagle M et al., Risk factors for late or no prenatal care following Medicaid expansions in California, Maternal and Child Health Journal, 2000, 4(4):251-259.

10. Goldani MZ et al., Trends in prenatal care use and low birthweight in southeast Brazil, American Journal of Public Health, 2004, 94(8): 1366-1371.

11. Gama SG et al., Factors associated with precarious prenatal care in a sample of post-partum adolescent mothers in maternity hospitals in Rio de Janeiro, Brazil, 1999-2000, Cadernos de Saúde Pública, 2004, 20(Suppl.1):S101-S111 (in Portuguese).

12. D'Ascoli PT et al., Parental factors influencing patterns of prenatal care utilization, Journal of Perinatology, 1997, 17(4):283-287.

13. Cooney JP, What determines the start of prenatal care? prenatal care, insurance, and education, Medical Care, 1995, 23(8):986-997.

14. Kim HG et al., Antenatal psychiatric illness and adequacy of prenatal care in an ethnically diverse inner-city obstetric population, Archives of Women's Mental Health, 2006, 9(2):103-107.

15. Tough SC et al., The relationship between self-reported emotional health, demographics, and perceived satisfaction with prenatal care, International Journal of Health Care Quality Assurance Incorporating Leadership in Health Services, 2004, 17(1):26-38.

16. Johnson AA et al., Determinants of late prenatal care initiation by African American women in Washington, DC, Maternal and Child Health Journal, 2003, 7(2):103-114.

17. Bassani DG, Olinto MT and Kreiger N, Periodontal disease and 
perinatal outcomes: a case-control study, Journal of Clinical Periodontology, 2007, 34(1):31-39.

18. Kessner DM et al., Infant death: an analysis by maternal risk and health care, in: Contrast in Health Status, Vol. 1, Washington, DC: National Academy of Sciences, 1973, pp. 50-95.

19. Victora CG et al., The role of conceptual frameworks in epidemiological analysis: a hierarchical approach, International Journal of Epidemiology, 1997, 26(1):224-227

20. Bustan MN and Coker AL, Maternal attitude toward pregnancy and the risk of neonatal death, American Journal of Public Health, 1994, 84(3):411-414

21. Kogan MD et al., The changing pattern of prenatal care utilization in the United States, 1981-1995, using different prenatal care indices, Journal of the American Medical Association, 1998, 279(20):1623-1628.

22. Heaman MI et al., Inadequate prenatal care and its association with adverse pregnancy outcomes: a comparison of indices, BMC Pregnancy and Childbirth, 2008, Vol. 8, Article 15, <http://www.biomedcentral. com/1471-2393/8/15>.

23. Nicholson WK et al., Prenatal patients' views of prenatal care services: a medical center-based assessment of knowledge and intent to use support services, Ethnicity \& Disease, 2004, 14(1):13-20.

24. Olinto MTA et al., Determinants of malnutrition in a low-income population: hierarchical analytical model, Cadernos de Saúde Pública, 1993, 9(Suppl. 1):14-27 (in Portuguese).

25. Malloy MH, Kao TC and Lee YJ, Analyzing the effect of prenatal care on pregnancy outcome: a conditional approach, American Journal of Public Health, 1992, 82(3):448-450.

26. Collins JW, Jr., and David RJ, Differences in neonatal mortality by race, income, and prenatal care, Ethnicity \& Disease, 1992, 2(1):18-26.

27. Alexander GR and Kotelchuck M, Assessing the role and effectiveness of prenatal care: history, challenges, and directions for future research, Public Health Reports, 2001, 116(4):306-316.

28. Patel $V$ et al., Effect of maternal mental health on infant growth in low income countries: new evidence from South Asia, BMJ, 2004, 328(7443):820-823

29. Surkan PJ et al., Maternal depressive symptoms, parenting selfefficacy, and child growth, American Journal of Public Health, 2008 98(1):125-132.

30. Kotelchuck M, An evaluation of the Kessner Adequacy of Prenatal Care Index and a proposed Adequacy of Prenatal Care Utilization Index, American Journal of Public Health, 1994, 84(9):1414-1420.

\section{RESUMEN}

Contexto: Para mejorar la aceptación de la atención prenatal, es importante conocer la forma en que la atención prenatal varía en función de actitudes maternas y factores sociales y demográficos.

Métodos: Se recolectó información de 611 mujeres postparto en Porto Alegre al sur de Brasil, sobre variables sociales y demográficas, atención prenatal, paridad, planificación del embarazo, intentos de aborto inducido, satisfacción con el embarazo y satisfacción respecto a la relación con el padre del hijo. Se utilizó regresión logística multinomial para evaluar las asociaciones entre estas variables y si el uso de la atención prenatal por parte de las mujeres fue adecuado, parcialmente inadecuado o inadecuado.

Resultados: Aproximadamente el 40\% de las mujeres tuvieron atención prenatal inadecuada o parcialmente inadecuada. Después de ajustar por otras covariables, incluida la satisfacción con el embarazo, las mujeres que tuvieron un embarazo no planeado tuvieron una probabilidad significativamente mayor que las mujeres que habian planificado su embarazo, de haber recibido una atención prenatal inadecuada (razón de momios, 2.0). También, el no vivir con el padre del hijo (2.8) y la insatisfacción con el embarazo (2.1) estuvieron asociados con el uso inadecuado de la atención prenatal. Las mujeres que estaban teniendo su segundo parto o un parto de mayor orden tuvieron una probabilidad significativamente mayor de reportar un uso inadecuado de la atención prenatal que las mujeres que estaban teniendo su primer parto (3.9-9.0). El ingreso familiar estuvo inversamente asociado con una atención inadecuada.

Conclusiones: El estudio sugiere que las actitudes maternas pueden ser importantes para una atención prenatal adecuada. Debe crearse intervenciones dirigidas a alentar a aquellas mujeres que tengan actitudes maternas negativas, para que hagan uso de la atención prenatal, así como para asegurar que tengan acceso a la atención que necesiten.

\section{RÉSUMÉ}

Contexte: Pour améliorer l'adoption des soins prénatals, il importe de savoir dans quelle mesure le recours à ces soins varie en fonction des attitudes maternelles et des facteurs sociodémographiques.

Méthodes: Une information relative aux variables sociodémographiques, aux soins prénatals, à la parité, à la planification de la grossesse, aux tentatives d'avortement, à la satisfaction face à la grossesse et à la satisfaction quant à la relation avec le père de l'enfant a été recueillie auprès de 611 femmes post-partum de Porto Alegre, dans le sud du Brésil. Les associations entre ces variables et l'utilisation adéquate des soins prénatals, partiellement adéquats ou inadéquats ont été évaluées par régression logistique multinomiale.

Résultats: Environ 40\% des femmes avaient obtenu des soins prénatals inadéquats ou partiellement adéquats. Après correction d'autres covariables, y compris la satisfaction ressentie face à la grossesse, les femmes qui n'avaient pas planifié leur grossesse sont apparues significativement plus susceptibles d'avoir obte$n u$ des soins prénatals inadéquats, par rapport à celles qui avaient planifié leur grossesse (rapport de probabilités, 2,0). La non-cohabitation avec le père de l'enfant $(2,8)$ et l'insatisfaction face à la grossesse $(2,1)$ se sont également révélées associées à des soins prénatals inadéquats. Les femmes qui avaient déjà accouché une ou plusieurs fois sont apparues significativement plus susceptibles de déclarer des soins prénatals inadéquats que celles dont cet accouchement était le premier (3,9-9,0). Le revenu du ménage s'est révélé inversement associé aux soins inadéquats.

Conclusions: L'étude laisse entendre combien les attitudes maternelles peuvent être importantes à l'obtention de soins prénatals adéquats. Des interventions devraient être mises en place pour encourager les femmes présentant des attitudes maternelles négatives à recourir aux soins prénatals et pour assurer leur accès aux soins dont elles ont besoin.

\section{Acknowledgments}

The authors wish to thank Marcos P. Patussi for his careful review and helpful suggestions during the preparation of the final manuscript.

\section{Author contact: mtolinto@unisinos.br}

